\title{
THE VERNACULAR HERITAGE OF GJIROKASTRA (ALBANIA): ANALYSIS OF URBAN AND CONSTRUCTIVE FEATURES, THREATS AND CONSERVATION STRATEGIES
}

\author{
L. Dipasquale ${ }^{1}$, M. Carta ${ }^{1}$, S. Galassi ${ }^{1}$, A. Merlo ${ }^{1, *}$ \\ ${ }^{1}$ Department of Architecture, DAR|MED Lab, University of Florence, Italy- (letizia.dipasquale, massimo.carta, stefano.galassi, \\ alessandro.merlo)@unifi.it
}

Commission II - WG II/8

KEY WORDS: World heritage site, Vernacular heritage documentation, Balkan vernacular heritage, Building culture

\begin{abstract}
The old town of Gjirokastra (Albania), was included in the World Heritage List in 2005 thanks to the valuable presence of several remarkable examples of Ottoman-styled houses and in the integrity of the vernacular urban landscape. The urban structure is strongly influenced by the orography of the Drino valley and its slopes where the city was founded. Stone is the building material that characterizes the paving of the streets, the walls of the buildings and the roof coverings. The wood, mostly local, was used to build the frame structure of the upper floors and the roofs, in order to provide large windows and bright interior spaces. In December 2018, as part of the activities of the 3D Past project, founded by Eu Creative Europe Programme, Italian and Albanian students took part in a workshop in Gjirokastra. Such an initiative was designed to understand the tangible and intangible components of the vernacular heritage of Gjrokastra. In a multidisciplinary approach, students, professors, researchers and local experts analysed the morphological features of the historic center, the public spaces, and the traditional building systems. Traditional instruments such as the direct survey, the on-site observation and the interviews were adopted in combination with more innovative tools such as the laser scanner and the photogrammetry. This contribution not only illustrates the results of a multi-scale analysis, but it also highlights the transformations and threats that endanger the transmission of the unique characteristics of the city to the future generations. Moreover, it deals with the conservation strategies currently in use and some possible future measures that can contribute to the sustainable safeguard and development of the site.
\end{abstract}

\section{INTRODUCTION}

Gjirokastra, a small city in southern Albania, was added to the UNESCO World Heritage List in 2005, as a rare, outstanding and universal example of a well-preserved Ottoman town, which has preserved its residential vernacular architecture enabling the present generations to understand the diversity of urban societies in the Balkans, and to longstanding ways of life which today have almost disappeared. The interest in the protection of Gjirokastra's heritage arose in 1961 when it was proclaimed a "museum city". On that occasion 616 out of 1220 traditional buildings were declared protected monuments (Torresi, 2001; Riza, 2015).

Indeed, the morphology of the slopes of the Drino valley where the traditional ancient stone houses with grey slate roofs were built, the climate and the socio-economic conditions of their inhabitants influenced the morphology of the buildings. The choice of the place of foundation on rocky, steep and uneven mountain slopes overlooking the Drino valley, met a defensive need but created a number of severe limitations to the builders (Mezini, Pojani, 2015)

The Ottoman detached tower-houses, (in Turkish and Albanian kullë), which served a dual, living and defensive purpose, mark the urban vernacular landscape. They are the evidence of Gjirokastra's wealth and regional status in the time of Ottoman Empire, when generations of skilled craftsmen arrived at this town from neighbouring areas to carry out their construction.
Local stone is the main building material of the town: the walls, the roofs, the paving of the streets and the courtyards are made of blocks or slabs of local limestone and slate. Wood also plays an important role: the masonry reinforcement elements, the structures of the floors and the roofs and the uppermost walls are made of timber. The uppermost floors, with a timber structure (called çatma), a wooden lath and plaster, a row of windows and terraces are typical of Ottoman residential houses.

\subsection{The methods and the purpose of the investigation}

The World Heritage site "Historic Centres of Berat and Gjirokastra" was considered a case study as part of the "3D Past - Living \& virtual visiting European World Heritage” project, funded by the European Program Creative Europe. The Department of Architecture of University of Florence joined the project as a partner together with ESG/ Escola Superior Gallaecia (coordinator) and UPV/ Universidad Politécnica de Valencia.

The project was meant to investigate some World Heritage sites, which are still inhabited and are characterized by the presence of vernacular architecture. The main purpose of $3 \mathrm{D}$ past project is to show European citizens the good quality of vernacular architecture, its intangible local know-how and the preservation of fabric authenticity in the world heritage sites. The project aims to analyse both the tangible component of the heritage, concerning the evolution of the building types, the traditional techniques and materials, and the intangible one, regarding the craftsmen's empirical knowledge to build and maintain the

* Corresponding author 
vernacular buildings. In order to disseminate the knowledge about the inhabited vernacular dwellings of European World Heritage, the project involves both the use of new technologies and innovative tools for the representation of vernacular buildings, and the organization of workshops and seminars. The results are available on a digital platform to be created throughout the project and two publications: one dealing with the best practices of maintenance and conservation and the other that, using also augmented reality to show digital content through the book, deals with the systematization of the knowledge on the vernacular architecture of the chosen sites.

The activities carried out in Gjirokastra are aimed to analyze the local building through the use of the instruments of survey and digital representation and with the collaboration of students and local experts. The workshop, which was held in Gjirokastra from 17 to 21 December 2018, was attended by 28 Albanian students from the University of the Our Lady of Good Counsel based in Tirana, 12 students and researchers from the University of Florence, and local experts in architecture and traditional construction.

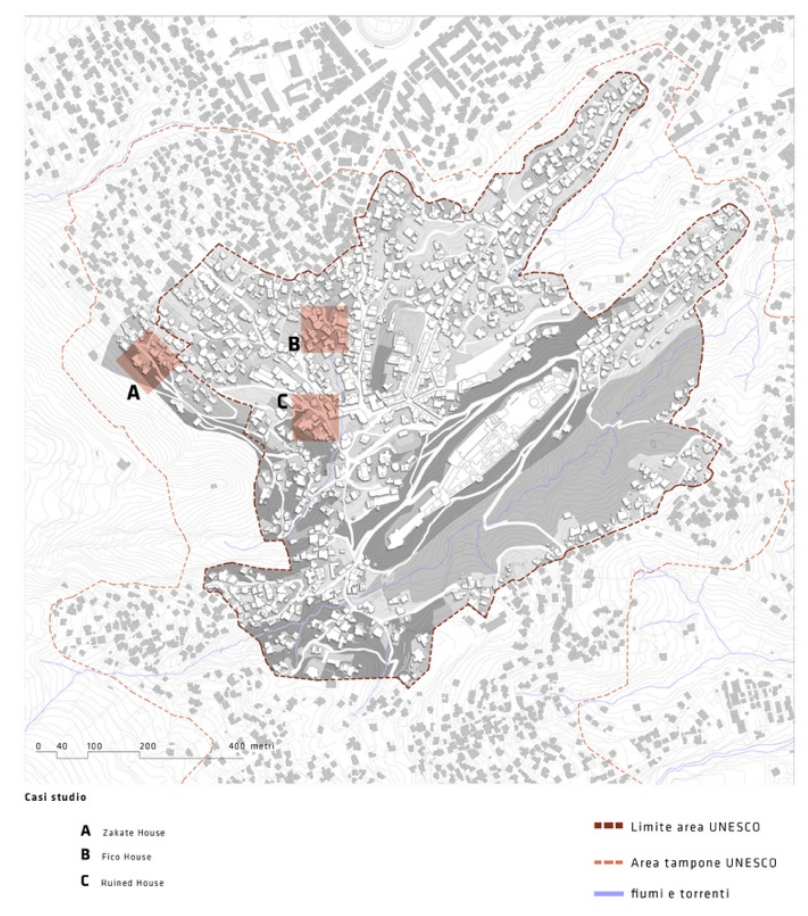

Figure 1. Plan of Gjirokastra and selected case studies (C) L. Giannone, E. Lamacchia).

The investigation activities were carried out adopting an interdisciplinary approach and using both traditional and advanced data gathering techniques. The first level of investigation was founded on range and image-based survey tools for the documentation of the three buildings which had been identified as case studies (Figure 1). The data, acquired through laser scanners, total stations, and photographic instruments, were processed to obtain $2 \mathrm{D}$ representations and $3 \mathrm{D}$ models, useful to understand the morphological and constructive characteristics of vernacular architecture and the main phenomena of degradation. A second level of analysis concerning the building elements and their structural behavior, required the use of tools of direct survey observation, interviews and the compilation of analysis sheets. A third level of investigation concerned the urban scale in order to reconstruct the evolution of the urban settlement and the research group worked on the physical-morphological characteristics of the site and the reasons for the location of the historical and contemporary settlement, the investigation on the dynamics of formation of ancient and recent urban fabrics, the analysis of urban functions and their variation over time. The analysis in the field was based on direct observation, photography and the compilation of sheets that allowed the drafting of maps at the various scales.

\section{THE TERRITORIAL AND URBAN STRUCTURE}

\subsection{Location, landforms and structures}

Gjirokastra presented the wide range of the orographic features of the wide valley of the Drino river. This town, stretching South-east / north-west and enhancing its defensive potential and its position of control between the Ionian Sea and the Balkans, became a meeting place for the Greek, Roman, Byzantine and Ottoman cultures. Until the end of the nineteenth century the perimeter of the center, was drawn by the lines leading to the Castle, corresponding to the ridges perpendicular to the Mali $i$ Gjerë massif (alt. approx. 1800m. above sea level). From the 1900s and especially after the end of the Second World War, a progressive expansion of the town could be identified in the valley. The Castle is about $350 \mathrm{~m}$ above sea level, at the beginning of the southernmost ridge, from which it extends over the valley. Schematically, the main structure of Gjirokastra consists of two ridges standing out from the massif: the Rruga Pazari i Vjeter Pllake runs on the first ridge (in the South), dominated by the Castle, and the Rruga Alqi Kondi runs on the second ridge further north.

At the junction point of the two ridges towards the mountain, just where the valley that separates them is not very wide, we find the Bazaar district, the true ordering element of old Gjirokastra, with its characteristic crossroads. From the bazaar, in fact, the Rruga Ismail Kadare follows the slope of the ground and becomes part of a sort of chessboard located on the wide slope overlooking the valley and lying to the limit of the old center, a ravine at which the extension towards the valley of the Bulevardi 18 Shtatori arrives. This important road, perpendicular to the river, marked the expansion of the modern city on the valley; the long Rruga Doktor Vasil Laboviti starts uphill from the Bulevardi 18 Shtatori, a natural link between the modern city below and the old city above. Within this scheme, the standing points of the urban center of Gjirokastra are detectable: the Castle with an unfortified village but with an organized defensive system consisting of fortress-houses, lookouts on the valley. The fortress- houses were organized in "neighborhood unit" based on parental or "clan" principles. The large size of the most important buildings, their "individual" and proudly independent nature, drew a urban structure with irregular blocks, an articulated road hierarchy, and a large amount of green spaces inside the blocks: greenery was widespread among the buildings and the spaces between the properties, with extensions of various shapes and densities. One can perceive the ancient presence of small parks, orchards, gardens where now uncultivated areas cover the slope below the Castle.

\subsection{Urban model}

The density is relatively low (compared to the fabrics of the historical centers of the Arab or the medieval towns of western Europe), characterized by the particular building structures of the tower-houses perceive. This does not prevent an exceptional cohesion and coherence of the urban structure and the building fabric as a whole. It is an urban structure that mirrors a relatively horizontal society, with strong individualities competing with each other. For this reason, the town is not divided into zones according to hierarchical principles. The main building 
organisms with their reference area are organized in blocks or aggregates (or neighbourhoods), where filter spaces articulate the relationships between private and public spaces. The uniformity of the building materials (local stone) (Figure 2), the volumetric layouts and the layout of the public paths, create a cohesive, recognizable and unique historic center. Some construction measures designed during the socialist dictatorship transformed some wider public spaces into the historical fabric, widening the section of some streets, taking advantage of some changes in altitude, replacing few historical buildings. The buildings were connected indirectly with the street through a gradual system of filters, made up of courtyards, gardens and private and semipublic spaces. Traditional road pavements are made of stone too and two different local stones are used in accordance with the variety of solutions to overcome the problem of different slopes, which sometimes made stairways necessary.

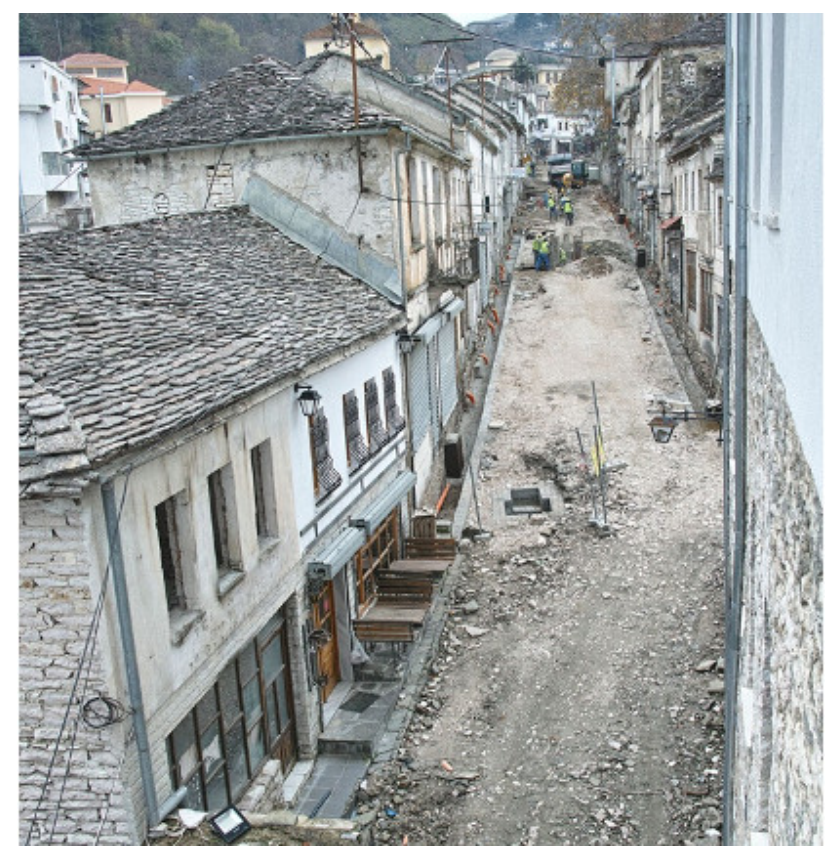

Figure 2. Gjirokastra roads being restored (C M. Carta, 2019).

\section{ANALYSIS OF THE MORPHOLOGICAL AND CONSTRUCTION FEATURES OF THREE CASE STUDIES}

\subsection{Methodology of analysis}

During the worskhop three buildings were selected as case studies to analyze in detail and understand their architectural morphology, construction systems, structural behavior and state of conservation. The three buildings identified (the Fico house, the Zekate house and the Dalipi house), are located in the Palorto district, in the valley in the North of the historic town. They differ for their period of construction, their state of conservation and their current usage. The digital survey with a $3 \mathrm{~d}$ laser scanner, photographic instruments and a drone was supported by analysis sheets on the usage and conservation status of the building, the building techniques used for the horizontal and vertical structures, the outside sitting space.

\subsection{Zekate house}

The first selected building stands out for the good state of conservation of its architectural and construction elements, that constitute a good starting point for the study of the fortified house type, called kulla (Figure 3 ).
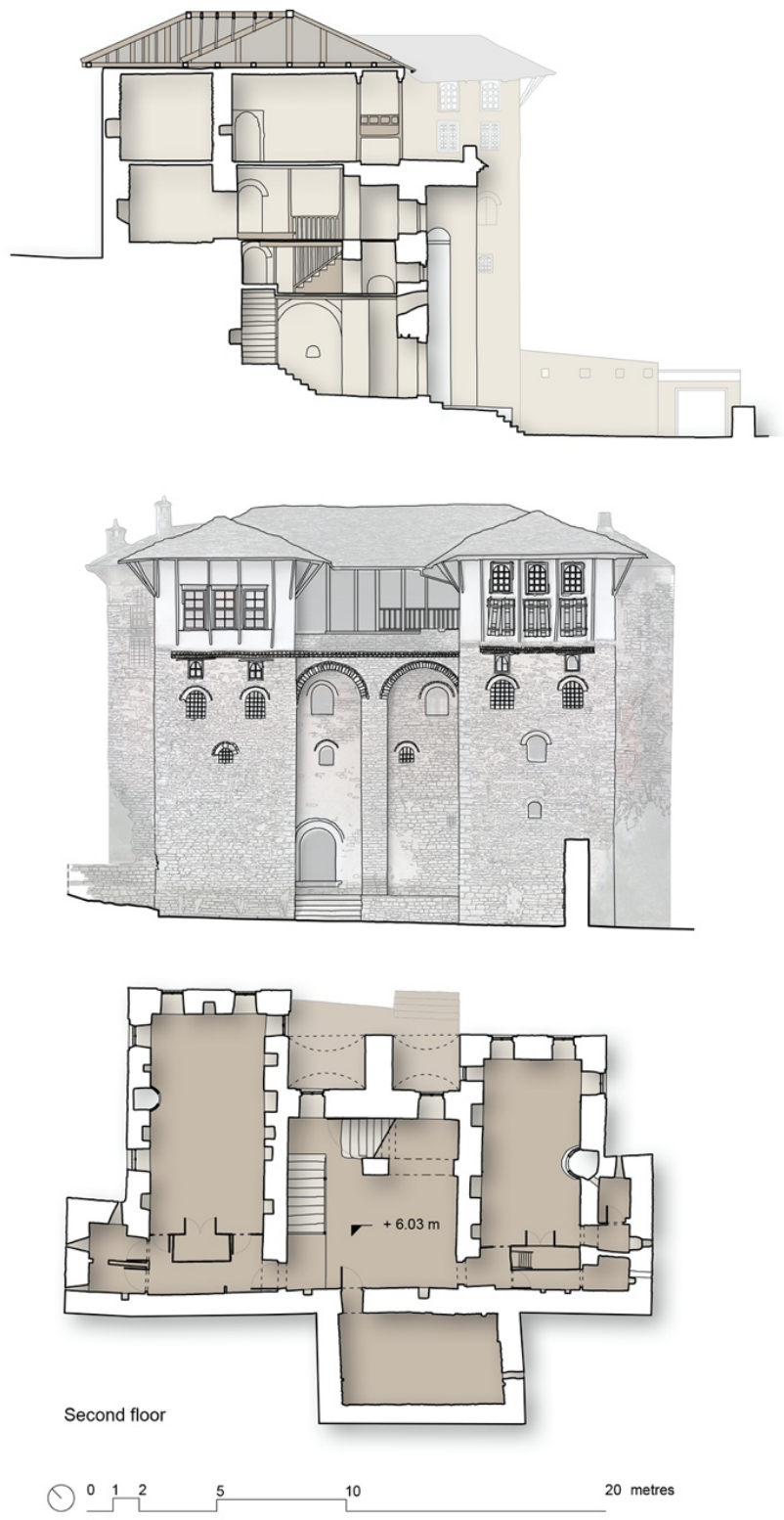

Figure 3. Plan, main façade and cross section of Zekate house (Survey: G. Cara, K. Kumi, M. Gega, F. SHillaku, J. Tuci. Graphic editing: E. Lamacchia).

The Zeko family's house, is located on the edge of the town, on a steep slope, in a dominant position towards the south-western part of Gjirokastra. A north-eastern garden and three stone-paved courtyards on the main south-west front surround the building. The house is slender and compact and has the typical defensive characteristics of this typology of building, with few openings on the lower floors and high walls all around the courtyard. The house is included in the national list of first class monuments. The building, now used as a museum house, was built starting from 1811, and underwent a first restoration in the years 19681975 (Riza, 2015), and a second one in 2004-2005. The restoration measures were carried out with a conservative approach and did not alter significantly the planimetry and the used construction systems. The planimetric scheme is composed of two lateral rectangular blocks and a central connection element, with two large arches (kemer) on the facade, which connect the two wings and support the top floor terrace, a privileged point of view towards the valley of the Drino. 


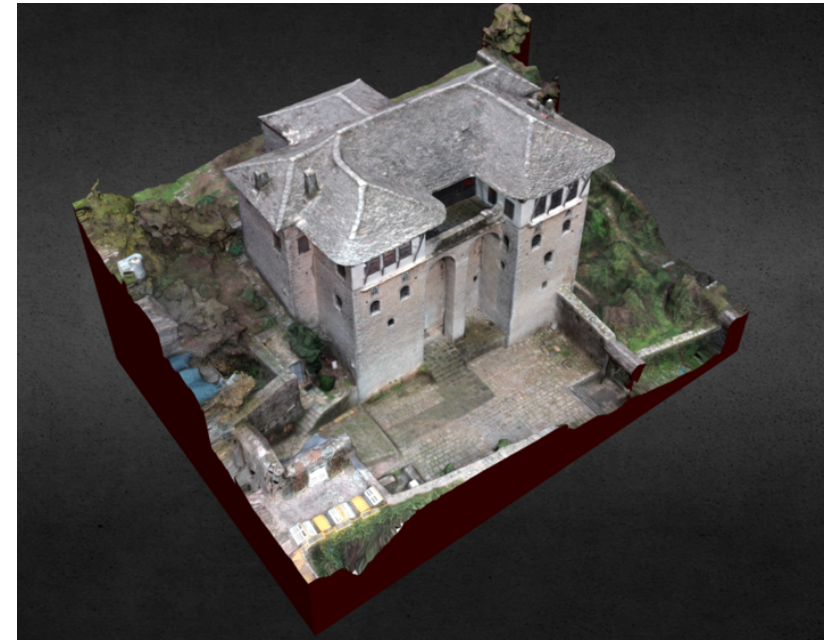

Figure 4. 3D model of Zekate house (C F. Frullini).

The functional organization is based on the distribution of the service spaces on the ground and mezzanine floors and the residential rooms on the upper floors. The ground floor hosts a small space for the reception of occasional visitors and a vaulted storeroom (kube) to store and mill cereals, as well as to keep agricultural equipment. The ground floor is also the location of the water cistern, a common and often present element in the traditional houses of Gjirokastra. In fact, when choosing the city construction site, the defensive needs prevailed, and people preferred the most protected, but also the driest part of the Drinos Valley (Mamani, Mexhani, 2015). The supply of water was guaranteed by rainwater collected from the roof and stored in large cisterns located at the lower level of the house. The mezzanine floor contained a reception chamber and, over the cistern, a room used by the women for the storage of food and other household purposes.

The two residential floors have very different characteristics, due to their use in different seasons. The second floor, $2.8 \mathrm{~m}$ high, with small windows and thick stone walls, was used in winter (it is called dimerore which means the wintry floor). The third and last floor, $3.4 \mathrm{~m}$ high, with larger windows on the façades and thin walls with timber structure, was used in summer (it is called beharore which means summer floor). The location of the residential rooms on the upper floors has a defensive purpose too. The basic unit of the house is the residential room (called oda), which while maintaining the same dimensions on the different floors, presents different decorative elements in accordance with the people, family members or guests, who used it.

The second floor contains two main rooms (oda) with low couches (sofa) around three sides, and storage cupboards built into the walls. The fourth side of the room is occupied by the musandra, a large cupboard, which stored mattresses and other bedding during the day. The musandra concealed a short staircase leading to a small gallery (dhipato) where women and children retired during formal meetings reserved to the men of the house and to the guests (Doempke et al., 2012).

Each oda has also an adjacent toilet and bathroom (hamam), which were heated by the fireplaces in the main rooms.

The third floor contains the biggest reception room (oda e mirë, literally "good room") and two smaller rooms. The guest room has a great wealth of furnishings and decorative elements that are considerably richer than in the other parts of the oda: floral paintings on the walls, ceilings, and on the fireplace, wardrobes with moldings and notches. The ceiling is very finely carved and gilded and the windows have multicolored glasses. The backs of the third and fourth floors were respectively the kitchens for the winter and for the summer.

The central part of third floor hosts a wide terrace with a pergola (çardak) which offers a spectacular view over the town and valley below.

\subsection{Fico house}

The Fico House can be easily identified within the historic building fabric of Gjirokastra because of its golden yellow facade. Built in 1902, it is included in the national list of first class monuments. This building allows us to understand the changes that the Gjirokastra dwellings had at the beginning of the 20th century. In this period, in fact, the new buildings, while maintaining traditional planimetric and structural aspects, showed a stylistic evolution towards more western models. The present condition of the house is the result of the changes after two main phases of restoration, in 2012 and in 2014. The house is built on four levels and belongs to the two-winged typology, with the addition of a block in the southeastern part (Figures 5 and 6).
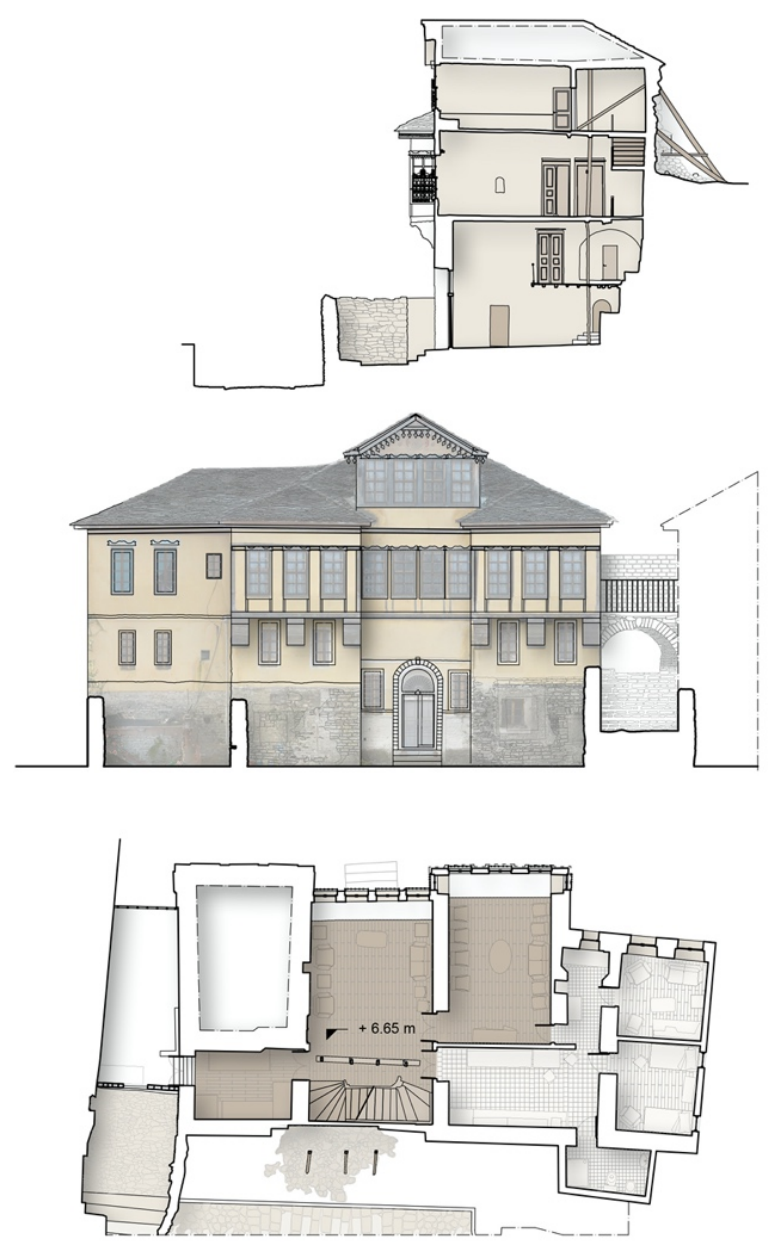

First floor

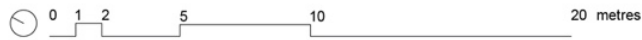

Figure 5. Plan, main façade and cross sections of Fico house (Survey: E. Barhi, F. Bregaji, J. Demiraj, G. Koli, J. Myftaraj. Graphic editing: E. Lamacchia). 
The functional organization follows the typical scheme of the tower house. With a central distribution space where the stairs are located, and the rooms on the sides. Between the building and the road there is the stone-paved courtyard surrounded by high walls, which is accessed by a large portal with a canopy. A door surmounted by an arch finely decorated with wrought iron provides the access to the building. On the ground floor there are the service spaces: the cistern (stera), the warehouse for food supplies and a storeroom. The ground floor is made of exposed masonry, while the others are plastered. The first floor, with a few windows, hosts the area dedicated to the preparation of the meals and the toilets. The second floor is the largest, with large windows on the main facade. Here there were two large guest rooms and the owners' master bedroom. The characteristic builtin wardrobes (musandra) are replaced by "modern" ones which are not fixed furnishings. The two projecting volumes of the second floor (called erker), rest on solid corbels and allow to increase the surface of the floor. The attic, located in the center of the house, on the top floor, is the most important space of the house (oda e mire) originally used as a summer residence. It has painted walls, a richly decorated ceiling and large and numerous windows that allow natural ventilation and lighting. The building is connected to the adjacent by means of a passage on the first floor and supported by a stone vault.

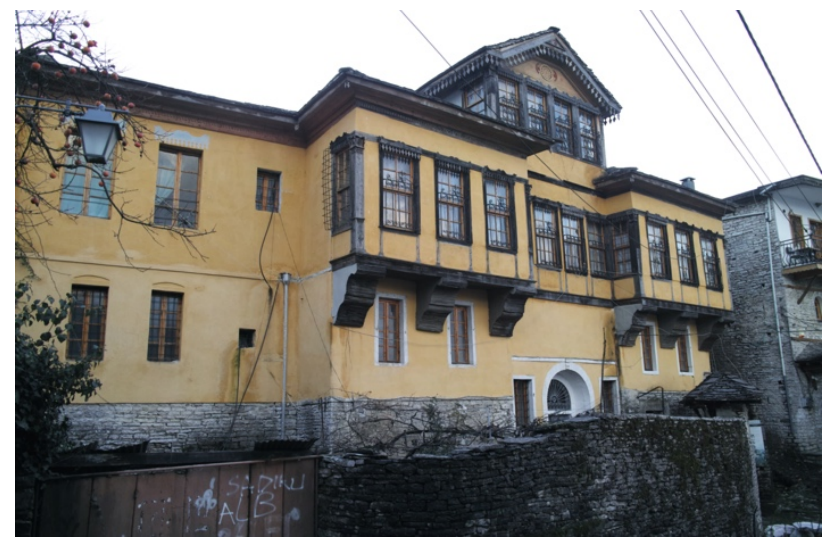

Figure 6. Main façade of Fico house (C M. Carta).

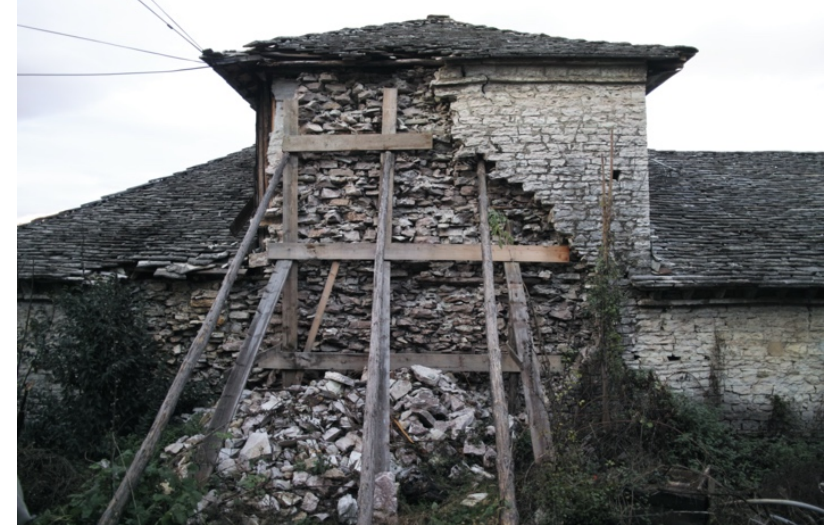

Figure 7. Back of Fico house (C M. Carta).

More recent restoration works mainly concerned the interiors and the distribution stairways, neglecting the structural health of the building. The most important deteriorations to date concern the deformation of the ceilings and floors and, above all, the partial collapse of the external facing of the stone masonry wall of the upper floor (Figure 7). The collapse is probably due to the lack of maintenance of the roof which may have caused water infiltration into the masonry.

\subsection{Dalipi house}

The third building, the Dalipi House, whose construction dates back to the beginning of the 20th century is included in the national list of second class monuments. The reading of the morphological components and construction features allows us to trace the history of the building, which has undergone numerous transformations, both at functional and a technical level. The reading of the transformation process has helped us to understand some recurrent problems in the buildings of Gjirokastra. A constant element in all the phases of transformation is the main entrance portal, characterized by a frescoed barrel vault. The building originally consisted of a single floor. In the first phase of the development of the building, the main facade had no openings and corresponded to the surrounding wall of the courtyard in front of the Dalipi stately home. Over the decades, the building has developed thanks to a series of clogging and superfetation interventions in the courtyard. First, a volume was created on the north-west side of the courtyard as a storage space and cold room used as food warehouse. The other volumes were arranged occupying the rest of the available space, leaving a path connecting the road and the stately home. These new spaces fulfilled the function of warehouse and stable. The ground floor walls were made of large limestone ashlars, tied with a small amount of mortar. The second floor, built at a later stage (there is no documentation of the date of construction), hosted the residential spaces: two bedrooms, a kitchen, a guest bedroom. The ground floor rooms in this second phase were used for the services of the house (bathroom and laundry) and the warehouse.

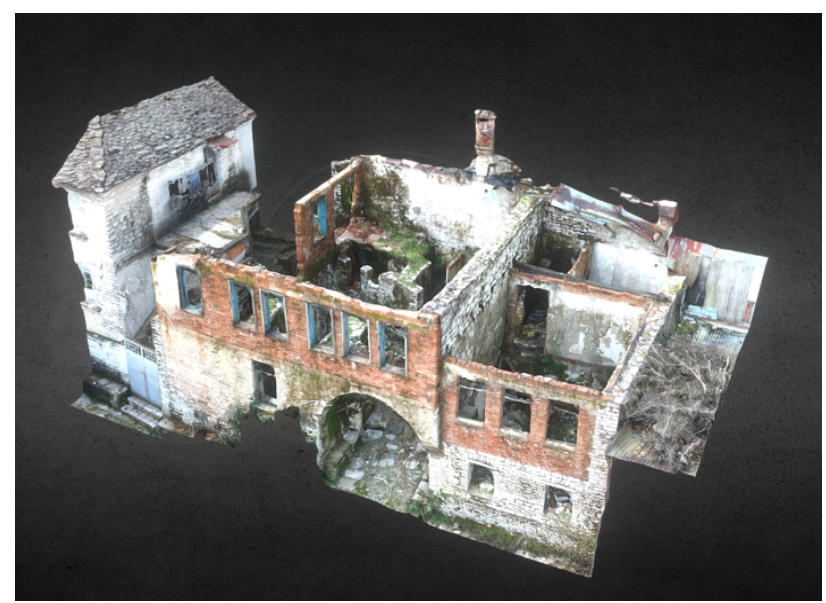

Figure 7. 3D model of Zekate house ( F. Frullini).

The first floor, originally built with a wooden structure called çatma, was destroyed by a fire, and was rebuilt in brickwork, courses of mixed headers and stretchers. After the fire, the wooden floors were replaced by a reinforced concrete and hollow tiles mixed structure. In the communist period the building was confiscated and entrusted to many families. During this period, the complex underwent further changes, including the opening of the ground floor windows. After 1999 the house was again entrusted to the Dalipi family. In this period a small room to the north-east was added, with timber structure walls. Between 2009 and 2010 part of the coverage collapsed. The collapse of the roof is a frequent event in Gjirokastra and it is probably due to the infiltration of water caused by the lack of maintenance of the roof slabs, which weaken the wooden support elements. Currently the building is in a state of abandonment with a process of increasing degradation, and continuous loss of wall portions (Figures 7 and $8)$. 

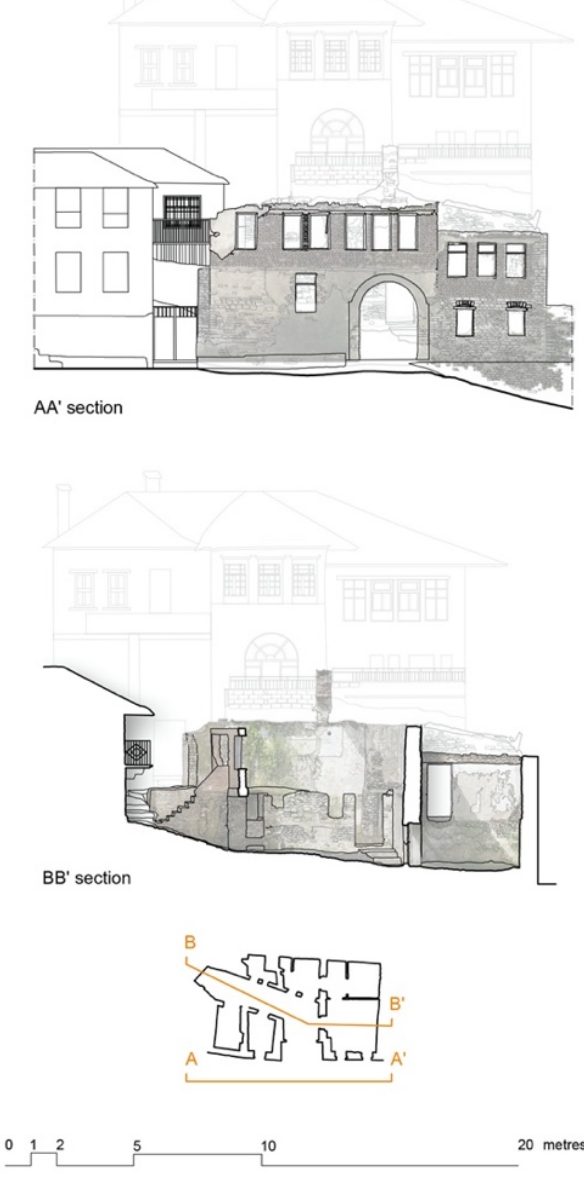

Figure 8. Cross sections and main façade of Dalipi ruins (Survey: K. Neli, J. Lamaj, E. Miho, J. Zajmi, M. Ballanca. Graphic editing: E. Lamacchia).

\subsection{Traditional building construction techniques}

In all the observed buildings, bearing walls are made of local limestone hewn blocks. The larger stones are placed on the external profiles, while the internal interstices are filled with smaller stones and pebbles. Stone blocks which occupy all or almost all the thickness of the wall, are used to connect the two faces of the wall. In the Zekate house the first 3 levels are built in stone masonry, with a thickness of about $110 \mathrm{~cm}$ on the ground and first floors, $90 \mathrm{~cm}$ on the second and $70 \mathrm{~cm}$ on the third. In the most recent Fico house, the thickness is $70 \mathrm{~cm}$ on the ground floor, 60 on the upper ones. The wall on the ground floor of the Dalipi house, which was built as a fence wall, is about $60 \mathrm{~cm}$ thick.

The stone elements are walled with lime and sand mortar. The mortar is generally more abundant in the external faces, while the central core is almost dry walled. This technique seems to have spread to limit the capillary ascent through mortar joints. Both in Zekate and Fico house horizontal timber ties are placed every 80$120 \mathrm{~cm}$ within the load bearing masonry.

They are placed along the wall direction, on both sides, and connected by transverse wooden pieces and a diagonal tie element at the corner. The elements placed on the external side of the wall are usually protected by a stone course. Horizontal timber ties are generally squared, and they are made of oak or chestnut. This system allows to connect the external faces of the masonry and create horizontal planes to lay the successive layers of stone blocks (Galassi et al., 2018a, 2018b).

Çatma is the building technique used for the walls of the upper floors, characterized by wide windows and reduced thickness. The çatma technique consists of a structure of vertical posts and horizontal battens, on which wooden boards are nailed (Figure 9). The filling of this frame is made of waste material and stones. The first layer of covering is composed of a $2 \mathrm{~cm}$ thick strawearth plaster. After the drying and the subsequent cracking of the plaster, a second $5 \mathrm{~cm}$ straightening coat of lime and wool, with a small amount of sand, is applied. The wood and clay plaster is laid on the first layer with a trowel and then it is floated for three or four days. A coat of lime milk paint is applied on it.

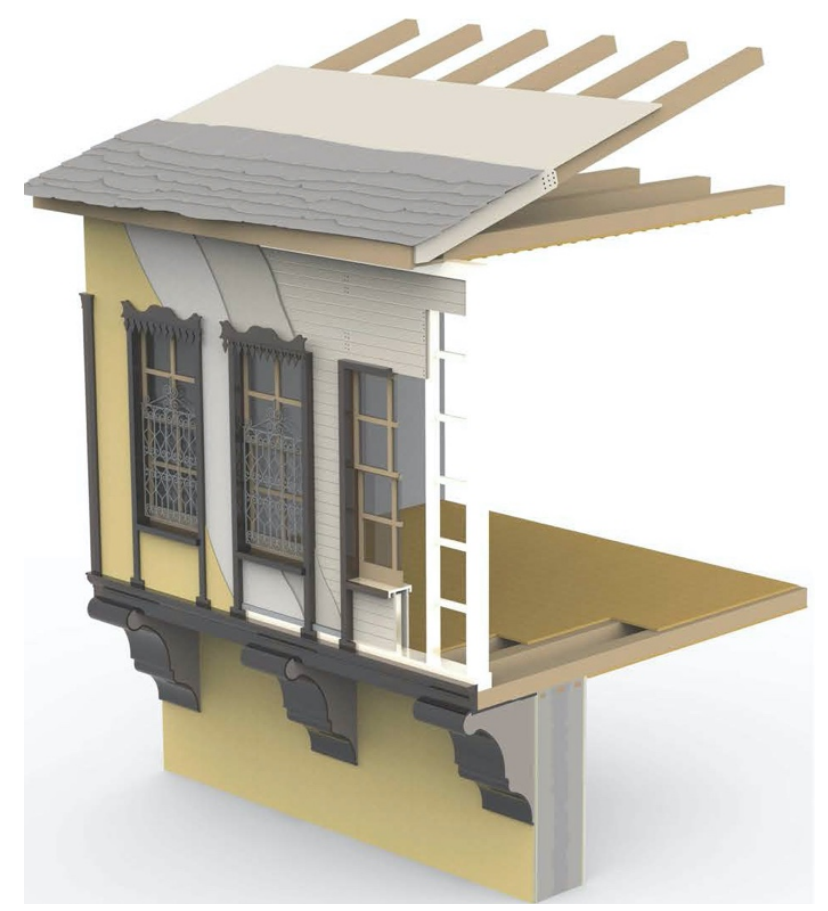

Figure 9. Detail of the çatma technique in Fico house (C) Koli Gentiana).

Barrel vaults are used to cover large spaces, such as entrances or tanks. They consist of blocks of accurately dressed stone with extremely fine bed and joints which are always walled with lime mortar. The vault is $35 \mathrm{~cm}$ thick, above construction debris and small stones are laid and levelled. When the masonry is not made of exposed stone, it is covered with a first layer of earthen mortar, then with another layer of lime and sand covering plaster. Lime and sand plaster are also used in cisterns.

The three buildings analyzed have a single framed timber floor. The floors consist of wooden joists - from $8 \div 12 \times 8 \div 12 \mathrm{~cm}-$ spaced each $35 \div 50$ centimeters and nailed on the horizontal timber element embedded in the walls. Planking consists of pine wooden boards with a cross section of $2 \times 20 \mathrm{~cm}$, which are placed at 90 degrees to the joists and nailed to them. There are no filling layers between the joists and the planking. Pine wood is also used for the windows, while the shutters are made of chestnut or beech, as well as the doors. Stairs are generally made of beech, oak or walnut wood (Mamani, Merxhan, 2012).

The supporting structure of the roof is made of wooden beams nailed together, which take on a rather complex hyper-static three-dimensional configuration, where all elements cooperate to 
support the heavy stone covering of the roof (Merxhani, Pompejano, 2015). A system of ceiling joists, of size $14 \div 18 \times 15 \div 20 \mathrm{~cm}$, is connected to the edge beams (taban) through riveted joints. On the edge beams (taban) also the principal rafters who support the ridge beam rest. Ridge beam and principal rafters are also supported by vertical posts (called baballëk), which rest on the horizontal beams (Merxhani, Pompejano, 2015). The principal rafters can also be supported by radial timber elements working as struts, that converges in the horizontal edge beams resting on a central wall or placed at 90 degrees on the ceiling joists. The common rafters, placed at a narrow distance, have a cross section of $5 \div 12$ × $5 \div 12 \mathrm{~cm}$. Wooden boards are fixed on them, at a distance of 5-8 cm from each other, on which the stone slabs are placed, without connections with mortar or metal hooks. The wooden false ceilings hide the structure of the roof, so it was possible to observe only part of the structure of the roof of the Zekate house, partially rebuilt following the last restoration. The grey slate stone slabs of the roof are approximately $1.5 \mathrm{~cm}$ thick and can vary in size. The larger slabs are generally used in the lower part of the roof which is to be the most stable, and smaller elements in the upper part so as not to overload the structure and reduce the thrust towards the lower layers and the gutter. The eaves protrude $50-60 \mathrm{~cm}$ and the rafters that support them (called testek) are in turn supported by timber elements connected to the wall, at the height of the lower floor.

\section{MAIN THREATS AND CONSERVATION STRATEGIES}

The historic town of Gjirokastra is legally protected by the Decree on the Museum City $(1961,2007)$, the Law on Cultural Heritage (2003) and its status as a World Heritage Site (2005). While the Decree and the World Heritage status protect the whole area of the historic town, the Law on Cultural Heritage places, in addition, more than 600 individual buildings under protection as cultural monuments of 1 st or 2 nd category. Despite the strict legal protection, the conservation status of many buildings is not good. A part of them is at great risk of neglect, abandonment, or subject to interventions disregarding the integrity of the building (Lamprakos, 2010). As also highlighted by the risk analysis report of the historic center of Gjirocastra (Scalet et al., 2014), the integrity of the site is under acute threat.

The risks to which the heritage of Gjirokastra is subject have both natural (seismic threat, wildland fires, erosion, landslides, rock falls) and human origins. Among the threats attributable to humans, the abandonment of the site from the inhabitants, certainly contribute to the general degradation of the building over time and the potential fire risk. The process of degradation and abandonment began with the fall of the regime and the economy in 1992. The municipal offices and merchants moved to the 'new towns' in the valley, many skilled builders and craftsmen emigrated to Greece and elsewhere. Due to the unstable political and economic situation in the country around 1997-1998 also most of the intellectual elite of Gjirokastra and homeowners hademigrated. Anti-government violence and fires in 1997 destroyed much of the bazaar, houses and much documentation on historic buildings. Since then many buildings have been abandoned and are now owned by many heirs who do not reside in town. The current inhabitants are often unable to pay the costs of restoration, and the unauthorized building and the misuse of the houses with the risk of damaging their authenticity and integrity are quite frequent. In addition, the private house owners sometimes do not recognize the value of the authenticity and integrity of the building, and do not understand that incompatible changes can be a problem. For example, replacing an entire slate roof (Figure 10) represents a great financial burden, 12 time greater than installing one of clay tile, and is not considered a priority by most of the inhabitants. Roofs maintenance and restoration are hampered by the restoration costs but also by a shortage of skilled craftsmen (Lamprakos, 2010).

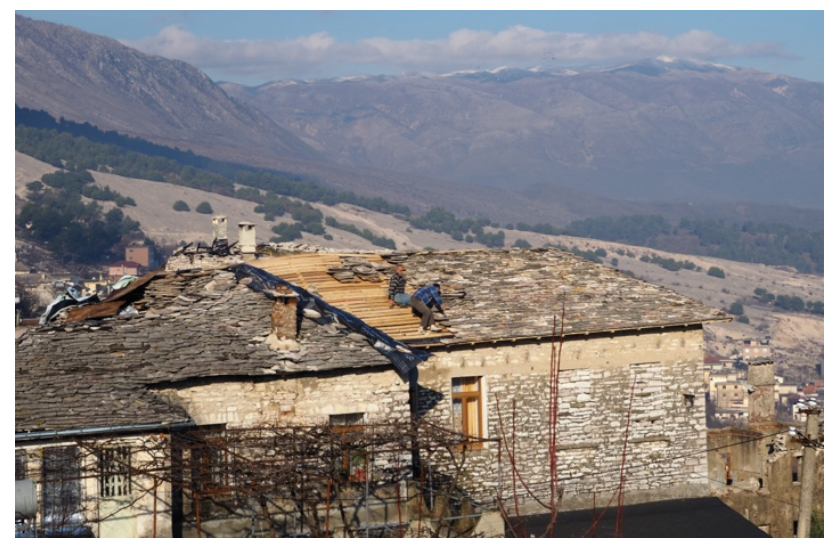

Figure 10. Traditional roof under restoration (C) L.Dipasquale, 2019).

To counter current threats, the most relevant initiatives are those carried out by two local NGOs: Gjirokastra Conservation and Development Organization (GCDO) and Cultural Heritage without Borders (CHwB). Both NGOs work for the conservation and development of cultural heritage in Gjirokastra, aiming to save decaying heritage of the town, and to rebuild interest and capacities. For more than ten years they have been carrying out activities both in terms of dissemination, training, restoration and active involvement of the inhabitants (Doempke et al., 2012). On the level of dissemination of knowledge on cultural heritage, they produced books and brochures, aimed at promoting educational activities, which often involve kids.

In terms of training since 2007, CHwB has implemented 38 Regional Restoration Camps, during which young people and students collaborate with local workers to recover parts of protected buildings. Regional Restoration Camps include activities of building conservation and interpretation, conservation of museum artifacts and interpretation, historical crafts and entrepreneurship, heritage interpretation.

Since 2004, Gjirokastra Foundation has undertaken numerous restoration projects, with an approach focused on reuse and sustainability, integrating training, business development, and community outreach. These include Zekate house (2004-2005), the rehabilitation of the bazaar (2007), the fountains and square of a 17th century bathhouse (2004), and Babameto House (20102013). Babameto House project (2010-2013) is one of the last examples of Restoration-Revitalization undertaken with abandoned buildings in Gjirokastra. This project brought together more than 70 owners of the property, two NGOs, and a partnership with state institutions. Now the house is opened to the public and is used as an example of revitalization of a typical Gjirokastra house. Babameto serves as a Center for Culture and Heritage, hosting cultural and tourism related events, as well as providing accommodation for tourists in form of a hostel.

Finally, among the most interesting activities of involvement of the local communities in the management of cultural heritage there is the Gjirokastra Experiential Tours project. This project aims to promote the local and natural resources of the area, through their inclusion in tourist packages, using them to develop 
experiential tourism based on the local cooking, dancing, singing, and other tradition. There is in fact a growing type of tourists attracted by the same architectural and urban quality of the historic city, more sensitive to the original and authentic characters of the context (García-Hernández et al., 2017).

\section{CONCLUSION}

Gjirokastra is the center of an emerging cultural tourism sector in southern Albania, which benefits from the natural and archaeological resources of the surrounding Drino Valley. The preservation policies of the landscape and of the environmental context where the old town is located should be promoted by the various levels of the administration, using as a guideline for the authorization of the transformations also the numerous studies, including the present one, that analyze the value of the architectural and urban heritage also in terms of interaction with the landscape denouncing the dynamics of transformation incoherent with the values that Unesco intends to preserve. Moreover, an attempt should be made to extend some of the safeguard measures and recommendations normally respected in the historical centre to the buffer zone in order to guarantee the architectural value of Gjirokastra in its context.

The built heritage of Gjirokastra is a precious source of social and economic development which needs specific measures for its preservation and development. On one hand it is important to develop professional tools such as management and development plans, a tourism development plan, and conservation guidelines, on the other it is essential to promote the involvement of inhabitants and in a shared management arising from the awareness of the value of the inhabited heritage. Some heritage conservation tools, as the national Cultural Heritage Law and the Institute of Monuments, are already present in Gjirokastra. What needs to be strengthened in Gjirokastra is a the rebuilding capacity and growing awareness of the importance of conservation as a response to a changed society and economy.

Systematic cultural actions such as the research we carried out could help to create the basis to identify appropriate and compatible conservation and intervention tools, and to increase the knowledge and awareness of the importance of a heritage which is universally recognized as exceptional. The creation of an integrated 3D database can, without any doubt, be useful for preservation, diagnostics, restoration, and management procedures.

The actions of knowledge and conservation must be used not only to protect the past, but also to build a future based on a development in which the inherited cultural heritage, closely linked to the environmental context, can improve the quality of life, the sense of community and the integration of the people in the places where they live.

\section{ACKNOWLEDGEMENTS}

We would like to thank Klenisa Galica (coordinator of the degree course in Architecture at the University of Our Lady of Good Counsel in Tirana, Elva Margariti (current Minister of Culture of the Republic of Albania) and Kreshnik Merxhani (architect at DRKK Gjirokastra), for the help provided in the organization and development of the workshop. Special recognition goes to all the Albanian students from the University of the Our Lady of Good Counsel based in Tirana and the students from University of Florence that held the workshop.
This paper is the result of the research project 3D Past - "Living \& virtual visiting European World Heritage" [Grant Agreement Ref N 570729-CREA-1-2016-1-PT-CULT-COOP1], which was co-funded by the European Union, under the programme Creative Europe (2016-2020).

\section{REFERENCES}

Doempke, S., Lulo Caca, A., Petrela, S. (eds.), 2012: Four Historic cities in the western balkans. Gjirokastra Conservation and development Organisation, Tirana

Galassi, S., Dipasquale, L., Ruggieri, N., Tempesta, G., 2018a: Andalusian timber roof structure in Chefchaouen, Northern Morocco: construction technique and structural behavior, Archit. Eng. 24 (3), 04018012 (2018) 10.1061/(ASCE)AE.19435568.0000315

Galassi, S., Ruggieri, N., Dipasquale, L., Tempesta, G., 2018b: Assessment of the Moroccan Vernacular Timber Roof: a Proposal for an Eco-Friendly Strengthening System, Journal of Architectural Conservation, 24(3), 224-248. doi.org/10.1080/13556207.2018.1545105.

García-Hernández, M., De la Calle-Vaquero, M., Yubero, C., 2017. Cultural Heritage and Urban Tourism: Historic City Centres under Pressure. Sustainability, 9(8): 1346.

Lamprakos, M., 2010: Conservation of Gjirokastra, Albania. Onsite Review Report, edited by Aga Khan Award for Architecture.

Mamani E., Merxhani K., 2012: Construction Materials In Historical And Monumental Buildings - Gjirokastra. International Students' Conference of Civil Engineering, ISCCE 2012, 10-11 May 2012, p. 1-8, Epoka University, Tirana, Albania.

Merxhani K., Pompejano F., 2015: Preliminary studies on traditional timber roof structures in Gjirokastra, Albania. Vernacular Architecture: Towards a Sustainable Future Mileto, Vegas, García Soriano, Cristini (Eds.), p. 631-636; Taylor \& Francis Group, London.

Mezini, L., Pojani, D., 2015: Defence, identity, and urban form: the extreme case of Gjirokastra. Planning Perspectives, Vol.30, p. 397-428.

Podestà, S., Pompejano, F., Stagno, G., 2013: The wooden roof of Banesa e Skendulate in Gjirokastra, Albania: the role of the diagnostic test campaign in the structural safety evaluation. Advanced Materials Research Vol. 778 (2013), p. 911-918, doi:10.4028/www.scientific.net/AMR.778.911

Riza, E., 2015: Arkitektura dhe restaurimi i banesës së Zekatëve - Gjirokastër. Monumentet Instituti i Monumenteve të Kulturës, Tirana, 53/2015, p. 125-142.

Scalet M., Poletto D., Cavinato G.P, Moscatelli M, 2014: Disaster Risk Management of Cultural Heritage Sites in Albania, CNR IGAG, Rome

Torresi F.2001, Gjirokastra analisi ed indirizzi per lo sviluppo futuro, Fast Edit, Acquaviva Picena; 2001. 